\title{
遅発性脳血管攣縮に対するフルナリジンの有用性
}

一当センターにおける現況一

\author{
藤田 稠 清, 川口 哲 郎, 庄 瀬 祥 晃
}

\section{Flunarizine and FET Treatment of Delayed Vasospasm in Severe Subarachnoid Hemorrhage}

\author{
Shigekiyo Fujita, M.D., Tetsuro Kawaguchi, M.D., and Yoshiteru Shose, M.D. \\ Department of Neurosurgery, Hyogo Brain and Heart Center at Himeji, Himeji, Japan
}

\begin{abstract}
Summary : A cerebral $\mathrm{Ca}^{2+}$ overload blocker-flunarizine hydrochloride (F)- was used with excellent results for prevention of delayed ischemic neurologic deficits (DIND) in severe SAH.

Of the consecutive 108 patients (62 Fisher's group III) including 28 FET (F plus Vit. E and Trifluoperazine-calmodulin antagonist-) treated orally with this drug, only one in Fisher's group III developed DIND. The cause of the DIND was attributable to administration failure of flunarizine. The association of severe angiographic vasospasm was less frequent (18\%) in flunarizine treatment and even much less frequent (6\%) with FET treatment. There were no side-effects from flunarizine.

The results are much superior to those obtained in studies with nimodipine reporting that $10-30 \%$ of patients in Fisher's group III developed DIND and some of them died.

These highly benefical effects on delayed vasospasm might be attributable to better cerebral affinity and the strong cerebral protective effect of flunarizine, in conbination with the antivasoconstrictive effect of trifluoperazine.
\end{abstract}

\section{はじめに}

当センターで開発されたフルナリジン療法が DIND 防

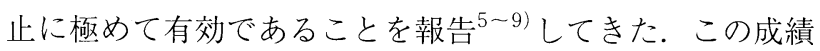
は他の $\mathrm{Ca}^{2+}$ 拮抗剤に比べ格段に良いが, angiographic vasospasm には有意の軽減作用を認めるものの, Fisher $\mathrm{III}^{3)}$ の $18 \%$ に diffuse severe 例がみられたため, この軽減 を目的として，抗カルモジュリン剤であるトリフロペラジ ン $(\mathrm{T})$, 更に過酸化脂質生成抑制作用のあるVitamin $\mathrm{E}$ (E)の併用 (FET 療法と呼ぶ)を試みているので報告する. FET それぞれの作用の概要を Table 1 に示した.
Key words :

- flunarizine

- trifluoperazine

- delayed vasospasm

- angiographic vasospasm

- ruptured cerebral aneurysm
方法

\section{1. 検查対象とフルナリジンなどの投与方法}

昭和 61 年 11 月から平成 2 年 10 月までの間に兵庫県立 姫路循環器病センター脳神経外科でフルナリジンその他が 投与された連続した破裂脳動脈瘤の 108 例を検査対象とし た. 手術時期, 術後の高血漿療法, 除外例, フルナリジン の経口(経鼻胃管)投与法などは前報) ${ }^{5)}$ と同様である. 最 後の 28 例ではフルナリジンに加えてトリフロペラジンを $30 \mathrm{mg}$ を分 4 で 4 日， $20 \mathrm{mg}$ を分 3 で 3 日， $15 \mathrm{mg}$ を分 2 で 7 日間, ユニベラニコチネートを $1200 \mathrm{mg}$ を分 4 で 4 日， $900 \mathrm{mg}$ を分 3 で 3 日， $600 \mathrm{mg}$ を分 2 で 14 日間で投 
Table 1 FET treatment on delayed vasospasm

\begin{tabular}{l}
\hline Flunarizine \\
$\left(\mathrm{Ca}^{2+}\right.$ overload blocker $)$ \\
Brain Protection \\
Improve blood rheology \\
Protect vascular endothelium \\
Selectivity to brain vessels \\
Absence of hypotension \\
Vitamin E \\
(Free radical scavenger) \\
Trifluoperazine \\
(Calmodulin antagonist) \\
Anti-vasoconstriction
\end{tabular}

与した.

\section{2. その他}

DIND の判断および angiographic vasospasm の程度の 分類も前報5)6) と同じである。

\section{結 果}

\section{DIND の抑制 (全症例)}

Table 2 にFET 療法の 28 例を含むフルナリジン療法の 108 例の結果を示した。 DINDによる死亡は0であり, CT 上の梗塞巣の発生が Fisher III 62 例中 1 例に見られた がこの原因はフルナリジン血中濃度不足のためであった。 FET 療法 28 例中， 1 例にトリフロペラジンによる筋強剛 をみたが，中止によりこれは消失した。フフルナリジンによ る副作用はなかった。

\section{Angiographic vasospasm の抑制 (Fisher III のみ)}

Fisher III の症例における angoigraphic vasospasm の程 度とその発現頻度を Table 3 に示した. diffuse severeの発 現は対照群 14 例中 8 例 (57\%) と極めて高頻度であったの に対し，フルナリジン群で 22 例中 4 例 $(18 \%)$ に低下, FET 群では 17 例中 1 例 $(6 \%)$ と著明に低下した。症例数 が 3 群とも少ないが，FET 群では従来よく見られた広範 にわたる強度の angiographic vasospasm はほとんど見ら れず， mild または diffuse moderate になったことはFET 療法が angiographic vasospasm の低減に働いたものと考 えられる. FET 群の 1 症例を以下に呈示する.

\section{3. 代表 症例}

56 歳, 女性. 右椎骨動脈後下小脳動脈分岐部 動脈瘤.

平成 2 年 2 月 28 日 18 時自宅の前でしゃがみこんでいる のを発見され，近医に搬送，CT 上強いクモ膜下出血のた め当センターに転送途中に再破裂があった。来院時 Hunt and Hess grade $\mathrm{IV}^{10)}$, 呼吸も弱く挿管, 瞳孔縮小,
Table 2 Results of flunarizine treatment

\begin{tabular}{lcccc}
\hline & & $\begin{array}{c}\text { Delayed } \\
\text { none }\end{array}$ & $\begin{array}{c}\text { Ischemic Neurologic } \\
\text { lesion on CT }\end{array}$ & $\begin{array}{c}\text { Deficits } \\
\text { dead }\end{array}$ \\
\hline $\begin{array}{l}\text { Delayed } \\
\text { Ope. }\end{array}$ & 4 & 4 & 0 & 0 \\
$\begin{array}{l}\text { Fisher's } \\
\text { group II }\end{array}$ & 42 & 42 & 0 & 0 \\
$\begin{array}{l}\text { Fisher's } \\
\text { group III }\end{array}$ & 62 & 61 & $1 *$ & 0 \\
\hline Total & 108 & 107 & $1 *$ & 0 \\
\hline
\end{tabular}

*: administration failure of flunarizine, (including 28 FET cases)

Table 3 Angiographic vasospasm (Fisher's Group III)

\begin{tabular}{|c|c|c|c|}
\hline & Control & Flunarizine & FET \\
\hline None or mild & 2 & 10 & 12 \\
\hline Diffuse moderate & 4 VS-LD 1 & 8 & 4 \\
\hline Diffuse severe & $\begin{array}{cc}8 \text { VS-LD } & 2 \\
(57 \%) \text { VS-D } & 4\end{array}$ & $\begin{array}{l}4 \\
(18 \%)\end{array}$ & $\begin{array}{c}1 \\
(6 \%)\end{array}$ \\
\hline Total & 14 & 22 & 17 \\
\hline
\end{tabular}

VS-LD: low density caused by vasospasm

VS-D : dead due to vasospasm

Doll's eye 不良でCT 上右橋延髄前面に幅広く強い high density を認めた (Fig. 1)。脳血管写上は右 VA-PICA に小 動脈瘤を認めた (Fig. 2)ので，同日引きつづき lateral recumbent position にて開頭，偏位型有空クリップによる neck clipping を行うと共に，極めて堅い延髄橋右前面の 脳槽の凝血をつぶしながら最大限に除去した。手術直後か らフルナリジン, Vit E，トリフロペラジンの経鼻胃管投 与とアルブミンによる高血漿療法を行った。意識は順調に 回復し, day 8 の脳血管写上も軽度の vasospasm を認める のみ(Fig. 2)であった. day 30 には意識正常，水頭症に対 L V.P shunt を行い, 右顔面神経麻痺と右不全麻痺を軽 度に残し同年 6 月 2 日, 独歩退院した。

\section{考案}

\section{FET 療法について}

フルナリジンの強力な DIND 防止効果については，前 報5) に述べたが，本剤の効果の基本は細胞内での $\mathrm{Ca}^{2+}$ の over-load を防止 (すなわち $\mathrm{Ca}^{2+}$ over-load blocker ${ }^{2)}$ )する ことによっており，ここが他の $\mathrm{Ca}^{2+}$ 拮抗剤例えばニモジ ピンやニカルジピンなどと比べ DIND 防止効果がより強 い理由である。その効果は主に脳保護作用によるが,

Table 1 にあるようにその他多数の優れた作用の相乗的な 効果の結果としてDIND が強く抑制されたと考えられる. 多数あるフルナリジンの基礎的実験報告については前報 ${ }^{5}$ 6)9)に述べた。 


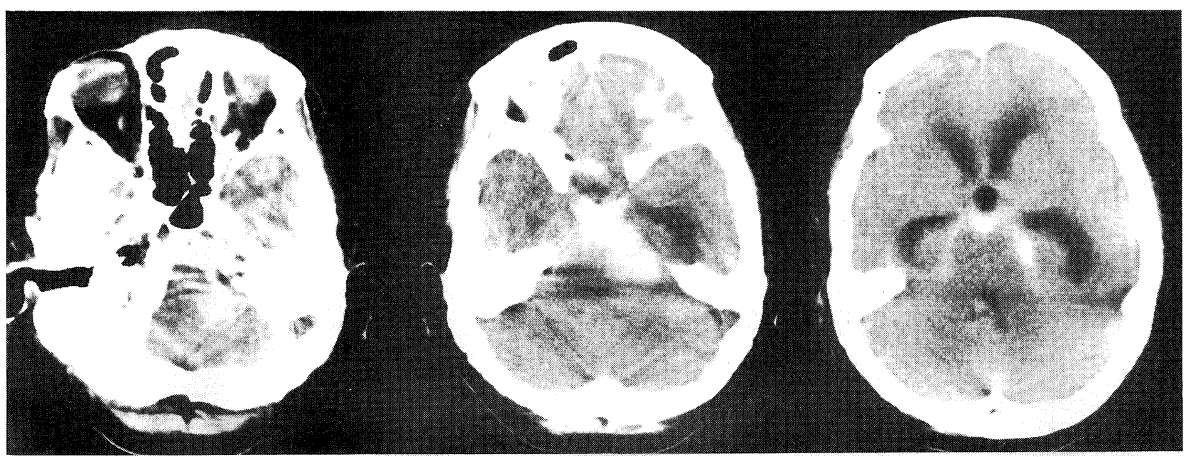

Fig. 1 Pre-operative CT of 56 year-old female with a severely ruptured right VA-PICA aneurysm were shown.

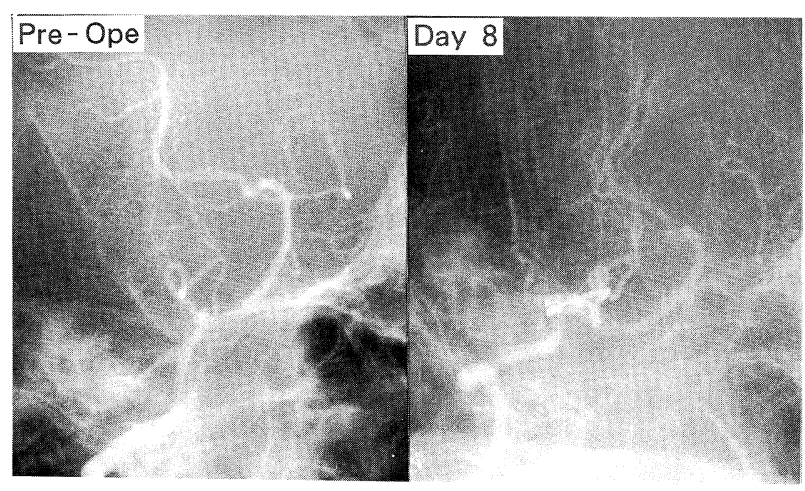

Fig. 2 Same case as in Fig. 1. Pre- and post-operative (day 8) angiograms were shown. Vasospasm of vertebal and other arteries were slight to mederate degree in post-operative angiogram despite severe subarachnoid hemorrhage.
Vitamin Eについては，その過酸化脂質生成抑制作用に より脳虚血に対して有用であることは周知の事実であり， DIND に対しても有用と考えられるとの報告 ${ }^{11)}$ がある.

一方，トリフロペラジンは市販されているフェノチアジ ン系化合物中最強の作用がある calmodulin antagonist で ある.カルモジュリンは細胞内の $\mathrm{Ca}^{2+}$ 受容蛋白質であり， カルモジュリン一分子あたり 4 個の $\mathrm{Ca}^{2+}$ と結合して標的 蛋白質を活性化する．血管平滑筋ではカルモジュリンと $\mathrm{Ca}^{2+}$ の結合によりアクチンとミオシンの重合がはじまり 筋の収縮が起こるので, calumodulin antagonist は脳血管 攣縮に対して抑制的に働くと考えられる. Peterson ら ${ }^{15)}$ の動物実験によると，すでに発生したvasospasmを寛解 しえないが，予防的使用では高用量で対照に比べ約 35\% 抑制されたとしている.

このようにトリフロペラジン単独では vasospasm の抑 制はそれほど強くないが， $\mathrm{Ca}^{2+}$ over-load blockerである フルナリジンとの併用により, angiographic vasospasm

Table 4 Effect of $\mathrm{Ca}^{2+}$ Antagonists on delayed vasospasm

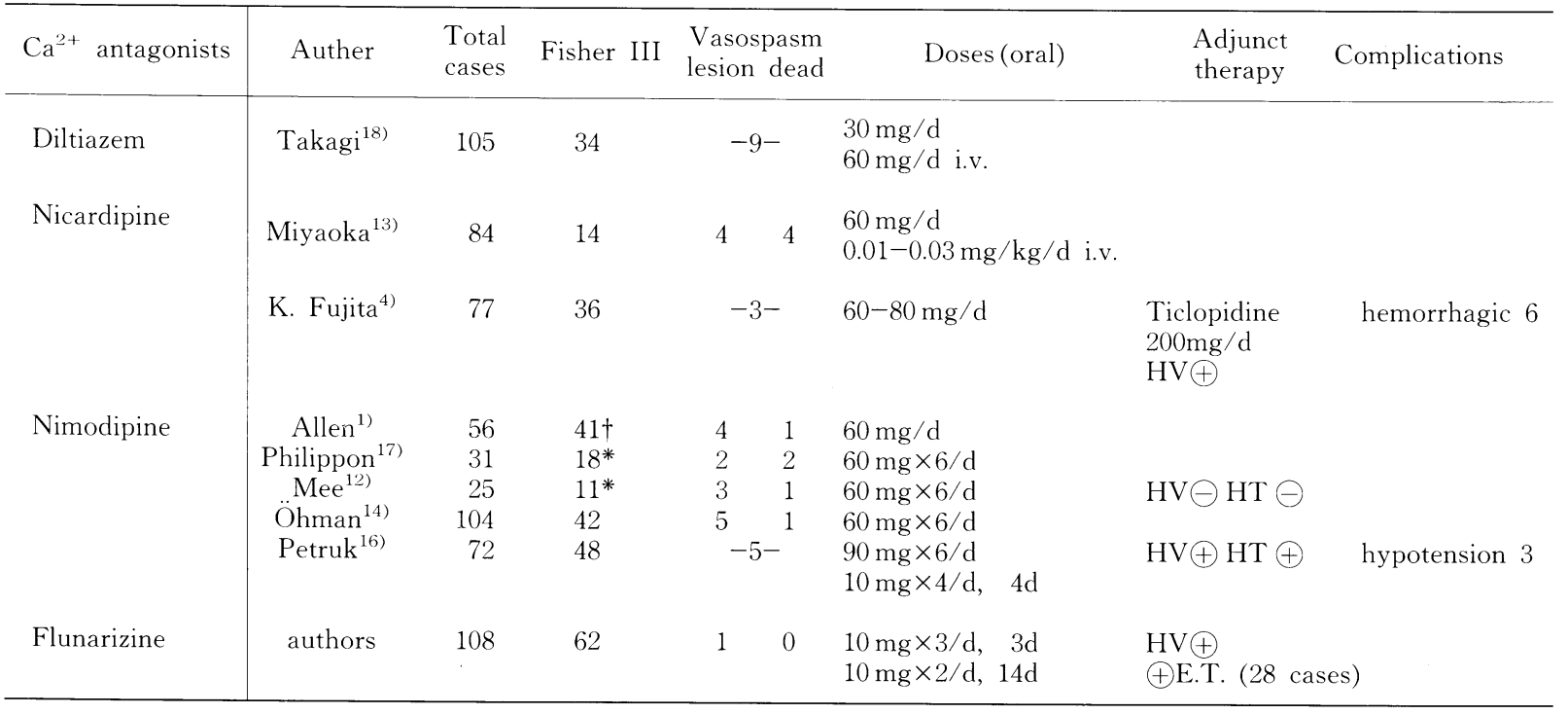

†: CT. Grade 3, *: CHD on CT, E: Vit. E, T: Trifluoperazine 
の軽減に相乗的に働いたことが十分に考えられる．FET 療法ではフルナリジン単独時よりも angiographic vasospasmの軽減により，効果の信頼性が向上したと考えられ る.

\section{2. 他の $\mathrm{Ca}^{2+}$ 拮抗剤との効果比較}

ジルチアゼム18)，ニカルジピン ${ }^{4) 13) ， ニ モ シ ゙ ヒ ゚ ン 1112) 14) ~}$ 16) 17)によるDIND 防止効果と本療法の効果とを比較した

(Table 4).この場合 Fisher らの group III における効果

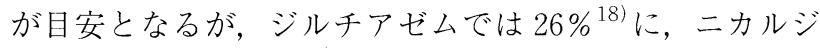
ピンでは $57 \%^{13)}$ と $8.3 \%{ }^{4)}$ にDINDを起こしている。 モジピンでも $10 \%^{16)}$ から $36 \%^{12)}$ の多数にDINDを起こし, そのうち $1 / 2-1 / 4$ が死亡している。これらのうちでは ニカルジピンの $8.3 \%{ }^{4)}$ が最も良いがチクロピジンを併用 したため出血性の合併症を 6 例とかなり高率に認めている これらに比べフルナリジンの経口投与はFisherの group IIIの 62 例中 1 例 $(1.6 \%)$ がDINDを起こしたが死 亡はなく，この 1 例も経口投与の失敗が原因と考えられる ので，フルナリジン療法は他の $\mathrm{Ca}^{2+}$ 拮抗剤を大きく上回 る効果をあげたと考える。

\section{おわりに}

1.DIND 防止にフルナリジン(経口)を使用した Fisher III 62 例を含む 108 例中, Fisher III の最重症の 1 例 に血中濃度不足による梗塞発生をみたが死亡例はない，

2.この成績は他の $\mathrm{Ca}^{2+}$ 拮抗棛による報告と比べ，本剂 が何倍か有効のようであった。

3. 最近はビタミン Eやトリフロペラジンの併用 $(\mathrm{FET}$ 療 法)により angiographic vasospasm も更に軽減し，よ り信頼できる療法となった。

4.FET 療法 28 例中，1例にトリフロペラジンによる筋 強剛をみたが，中止によりこれは消失した。フルナリ ジンによる副作用はなかった。

\section{文献}

1) Allen GS, Ahn HS, Preziosi, et al: Cerabral arterial spasm. A controlled trial of nimodipine in patients with subarachnoid hemorrhage. N Engl J Med 308: 619-624, 1983

2) Borgers M, Clerck FD, Van Reempts J, et al: Selective blockade of cellular $\mathrm{Ca}^{2+}$-overload by flunarizine. Inter Angio 3: 25-31, 1984
3) Fisher CM, Kistler JP, Davis JM: Relation of cerebral vasospasm to subarachnoid hemorrhage visualized by com. puted tomographic scanning. Neurosurgery 7: 1-9, 1980

4）藤田勝三, 山下晴央, 増村道雄, ほか：脳動脈瘤破裂後の Symptomatic vasospasm の予防効果の検討, 抗血小板剂及 び $\mathrm{Ca}^{++}$拮抗剤の併用療法群非投与群との比較. 脳神経外 科 16: 741-746, 1988

5) 藤田稠清： Flunarizine $\left(\mathrm{Ca}^{2+}\right.$ overload blocker) の DIND 防止効果. “スパズムシンポ講演集 脳血管攣縮, 中外医学 社, 1989, Vol. 4: pp 186-196

6）藤田稠清，川口哲郎：フルナリジンの遅発性脳血管攣縮防 止効果について. 脳卒中の外科 17: 345-348, 1989

7）藤田稠清：フルナリジンによるDIND 防止一特にその血中 濃度からみた改善策一。“スパズムシンポ講演集 脳血管攣 縮, 中外医学社, 1990, Vol. 5: pp 184-188

8) 藤田稠清, 川口哲郎, 伊地智昭浩, ほか：Flunarizine $\left(\mathrm{Ca}^{2}\right.$ ${ }^{+}$overload blocker) によるDIND 防止一血中濃度と脳血管 写を中心に. 脳卒中の外科 18: 44-49, 1990

9) Fujita S, Kawaguchi T, Shose 'Y, et al: Flunarizine treatment in poor-grade aneurysm patients. Acta Neurochir (Wien) 103: 11-17, 1990

10) Hunt WE, Hess RM: Surgical risk as related to time of intervention in the repair of intracranial aneurysms. J Neurosurg 28: 14-21, 1968

11）河野輝昭，森 和夫：脳動脈瘤破裂急性期における抗酸化 剤の投与一予報一。脳虚血と細胞障害一活性酸素とフリー ラジカルの関与一，にゅーろん社，1980, pp 172-177

12) Mee E, Dorrance D, Lowe D, et al : Controlled study of nimodipine in aneurysm patients treated early after subarachnoid hemorrhage. Neurosurgery 22: 484-491, 1988

13）宮岡 誠，石井昌三，佐野圭司： Ca ${ }^{++}$拮抗剤，塩酸 Nicardipine (Perdipine) の脳動脈瘤急性期手術例に対する効果一 全国18施設の集計より一。第42回日本脳神経外科学会 (大 阪), 1983

14) Öhman J, Heiskanen O. Effect of nimodipine on the outcome of patients after aneurysmal hemorrhage and surgery. J Neurosurg 69: 683-686, 1988

15) Peterson JW, Candia G, Spanos AJ, et al: The calmodulin antagonist trifluoperazine provides mild prophylactic protection against cerebral vasospasm after subarachnoid hemorrhage, but no therapeutic value. Neurosurgery 25: 917-922, 1989

16) Petruk KC, West M, Mohr G, et al: Nimodipine treatment in poor grade aneurysm patients. Results of a multicenter double-blind placebo-controlled trial. J Neurosurg 68: 505-517, 1988

17) Philippon J, Grob R, Dagreou F, et al: Prevention of vasospasm in subarachnoid hemorrhage. A controlled study with nimodipine. Acta Neurochir (Wien) 82: 110-114, 1986

18）高木卓爾，桑原正行，永井 肇，ほか：症候性脳血管攣縮 に対する $\mathrm{Ca}^{++}$拮抗剂 (diltiazem) の効果一基礎的, 臨床的 検討一。薬理と治療 10: 9-18, 1982 